\title{
Effect of amount of solution drunk on taste-aversion learning
}

\author{
NIGEL BOND and WAYNE HARLAND \\ School of Behavioural Sciences, Macquarie University \\ North Ryde, N.S.W. 2113, Australia
}

\begin{abstract}
Three groups of rats drank differing amounts $(0,2$, or $5 \mathrm{ml})$ of a $.25 \%$ saccharin solution just prior to injection of $.3 \mathrm{M} \mathrm{LiCl}$. In subsequent two-bottle preference tests, the group which drank $5 \mathrm{ml}$ displayed a stronger aversion to the saccharin than the group drinking $2 \mathrm{ml}$, which differed in turn from the group drinking $0 \mathrm{ml}$. These results confirm a previous finding that the strength of an animal's aversion is a direct function of the amount it consumed prior to poisoning.
\end{abstract}

Rats will learn to avoid a distinctly flavored solution if their initial exposure to that solution is associated with poisoning. This finding is of special interest because it demonstrates the ability of rats to learn an association despite long delays between the CS (taste) and the US (poisoning), even when only a single trial is employed (Revusky \& Garcia, 1970).

Several studies have investigated the effects of a variety of CS parameters on the strength of these conditioned aversions. For example, Dragoin (1971) has shown that taste aversion learning varies directly with the concentration of the solution drunk, and Revusky and Bedarf (1967) have demonstrated that preexposure to the CS reduces the degree of subsequent taste aversion learning.

In a recent study, Bond and Di Giusto (in press) found that the strength of a rat's aversion to saccharin was a direct function of the amount it consumed prior to poisoning. This result is in contrast to a previous report by Smith and Morris (1963) who found that amount consumed had no effect on aversion magnitude. However, the two studies differed in that Sinith and Morris employed the more sensitive two-bottle test, (Dragoin, McCleary \& McLeary, 1971) and this in conjunction with the values of $\mathrm{X}$-radiation they used may have produced maximal degrees of aversion over all levels of saccharin consumption. Elkins (1973) has poirited out that under such conditions aversion magnitude is an inadequate medsure of aversion strength. $\mathrm{He}$ has suggesied tirat whe animals display equivalent initial aversions, resistance to extinction may be the most appropriate test.

The present experiment sought to resolve this issue by further investigating the effects of amount of solution drunk on taste aversion learning. A two-bottle test was employed as in the Smith and Morris study, and the

The authors wish to thank E. Backhouse for his valuable technical assistance and Dr. E. Di Giusto for his comments on an earlier version of the manuscript. Reprints may be obtained from Nigel Bond.

This paper is sponsored by Michael Domjan who takes full editorial responsibility for the paper. animals were given repeated extinction tests as the measure of aversion strength.

\section{METHOD}

\section{Subjects and Apparatus}

Thirty-eight male Wistar rats weighing between $82 \mathrm{~g}$ and $156 \mathrm{~g}$ were used. All the subjects were approximately 45 days old. The subjects were housed in pairs in wire cages $(15 \times 24 \times 20 \mathrm{~cm}$ high) with free access to food for the duration of the experiment. Subjects were given access to water in separate drinking cages. These drinking cages were similar in dimensions to the home cages, but differed in that a $50-\mathrm{ml}$ graduated Richter tube could be inserted into either end of the cage. No food was available in the drinking cages.

\section{Procedure}

On each of the first 7 days, individual subjects were given access to tap water for $10 \mathrm{~min}$ per day. The water bottle was placed on opposite ends of the drinking cage on alternate days to train the animals to seek fluid from both ends.

On Day 8 (conditioning day) the animals were randomly assigned to one of the three treatment groups. Group OS was allowed to drink $5 \mathrm{ml}$ of water. Group $2 \mathrm{~S}$ drank $2 \mathrm{ml}$ of $.25 \%$ saccharin solution followed by $3 \mathrm{ml}$ of water. Group $5 \mathrm{~S}$ drank $5 \mathrm{ml}$ of the saccharin solution. Thus, all three groups were allowed to drink $5 \mathrm{ml}$ of fluid but differed in the amount of saccharin that they consumed. Two hours later each rat was injected intraperitoneally with $10 \mathrm{ml} / \mathrm{kg}$ of $.3 \mathrm{M} \mathrm{LiCl}$. Days 9 and 10 served as recovery days, each subject being given access to water for $10 \mathrm{~min}$ per day.

Starting with Day 11 , preference for saccharin vs. water was measured in eight daily $10 \mathrm{~min}$ preference tests. The position of the two solutions was alternated on succeeding days, and saccharin preference was measured as the percentage of the total fluid intake.

\section{RESULTS AND DISCUSSION}

The results are summarized in Figure 1. An overall two-way analysis of variance (ANOVA) performed on the data revealed both a significant amount effect $(\mathrm{F}=$ $21.34, \mathrm{df}=7, \mathrm{p}<.001)$, and a significant test day effect $(\mathrm{F}=29.55, \mathrm{df}=24, \mathrm{p}<.001)$ indicating that all three groups increased their preference for saccharin over days. There was no significant interaction. $t$ tests (two-tailed) performed on the overall group data 


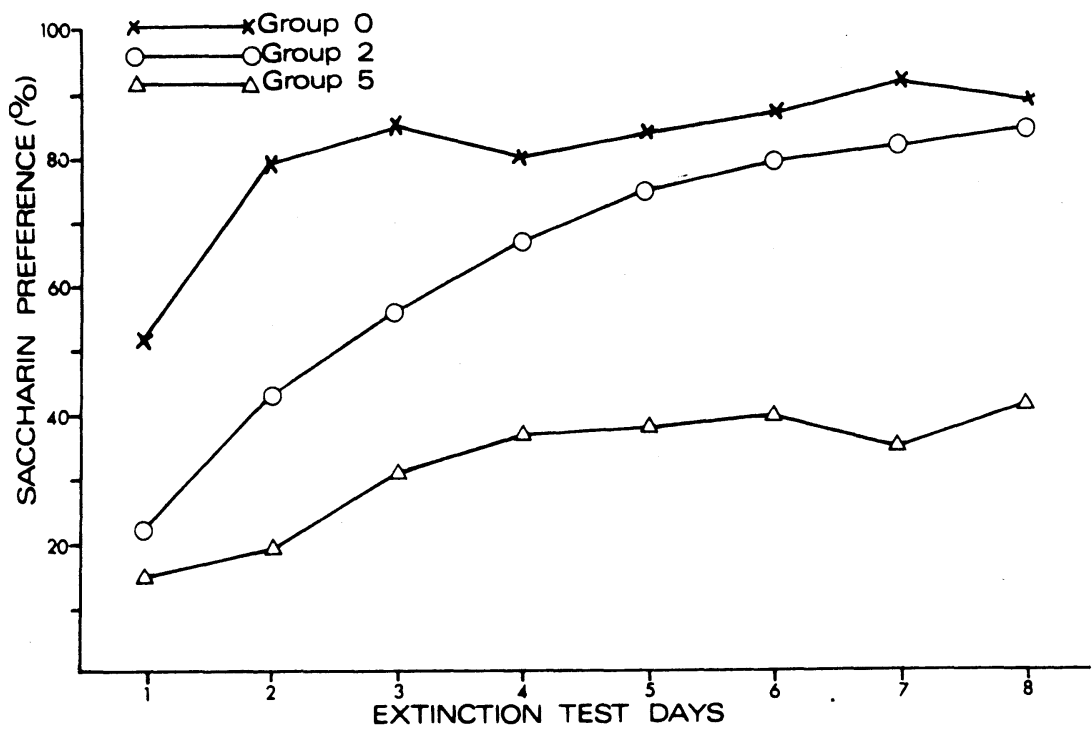

Figure 1. Mean saccharin preference for each group on each test day.

revealed significant differences between Group OS and both Group $2 \mathrm{~S}(\mathrm{t}=2.24, \mathrm{p}<.05)$ and Group $5 \mathrm{~S}(\mathrm{t}=$ $8.01, \mathrm{p}<.001)$. However, this result is not surprising since Group OS did not consume saccharin prior to poisoning and thus did not learn an aversion to it. Of more interest is the observed difference between Group 5S and Group 2S $(\mathrm{t}=3.49, \mathrm{p}<.01)$. Group 5S displayed a lower preference for the saccharin than Group $2 S$ indicating that these animals had learned a stronger aversion as a result of the greater amount drunk on the conditioning day.

The present results thus confirm the previous observation that amount drunk is a factor in the establishment of learned taste aversions (Bond \& Di Giusto, in press). Further, they extend this finding to the two-bottle test which is more frequently employed in such experiments. Suffice it to say that the generality of this phenomenon indicates that special care must be taken to control for its possible effects in experiments on taste-aversion learning.

\section{REFERENCES}

Bond, N. W., \& Di Giusto, E. Amount of solution drunk is a factor in the establishment of taste aversion. Animal Learning \& Behavior, in press.

Dragoin, W. B. Conditioning and extinction of taste aversions with variations in intensity of the CS and US in two strains of rats. Psychonomic Science, 1971, 22, 303-305.

Dragoin, W., McCleary, G. E., \& McCleary, P. A. A comparison of two methods of measuring conditioned taste aversions. Behavior Research Methods \& Instrumentation, 1971, 3, 309-310.

Elkins, R. L. Individual differences in bait shyness: effects of drug dose and measurement technique. The Psychological Record, 1973, 23, 349-358.

Revusky, S. H., \& Bedarf, E. W. Association of illness with prior ingestion of novel foods. Science, 1967, 155, 219-220.

Revusky, S. H., \& Garcia, J. Learned associations over long delays. In G. H. Bower \& J. T. spence (Eds.), The psychology of learning and motivation: Advances in research and theory. Vol. 4. New York: Academic Press, 1970.

Smith, J. C., \& Morris, D. D. The use of X-rays as the unconditioned stimulus in five-hundred-day-old rats. Journal of Comparative and Physiological Psychology, 1963, 56, 746-747.

(Received for publication October $31,1974$. ) 